\title{
Spontaneous intracerebral hemorrhage treated by neuroendoscopy - Technical note
}

Flávio Ramalho Romero', Marco Antôno Zanini², Luiz Gustavo Ducatti', Roberto Colichio Gabarra ${ }^{3}$

Division of Neurosurgery, Botucatu Medical School, São Paulo State University (Unesp), Botucatu, SP, Brazil.

\begin{abstract}
Spontaneous intracerebral hemorrhage $(\mathrm{SICH})$ is responsible for $10 \%-15 \%$ of the acute stroke. Hematoma or the occlusion of cerebrospinal fluid (CSF) flow by ventricular clotting can result in obstructive hydrocephalus, increasing intracranial pressure, which needs urgent decompression. We report our results of management of spontaneous deep cerebral hematoma by endoscopic approach.

\section{KEYWORDS}

Intracranial hemorrhages, neuroendoscopy, stroke.

\section{RESUMO}

Hematoma intracerebral espontâneo tratado por neuroendoscopia - Nota técnica

Hemorragia intracerebral espontânea é responsável por 10\%-15\% dos acidentes vasculares encefálicos agudos. Hematoma ou a oclusão da drenagem de liquor por coágulo sanguíneo pode resultar em hidrocefalia, aumentando a pressão intracraniana, com necessidade de tratamento de emergência. Relatamos nossa técnica na abordagem do hematoma cerebral profundo por neuroendoscopia.
\end{abstract}

\section{PALAVRAS-CHAVE}

Hemorragias intracranianas, neuroendoscopia, acidente vascular cerebral. 


\section{Introduction}

Spontaneous intracerebral hemorrhage (SICH) causes $10 \%$ to $15 \%$ of first-ever strokes, with a 30 -day mortality rate of $35 \%$ to $52 \%$ and half of the deaths occurring in the first 2 days. ${ }^{1,2}$ The common causes of SICH are hypertension, aneurysm, arteriovenous malformation (AVM), coagulopathies and vasculopathies. ${ }^{3-6}$ Death at 1 year for ICH varies by location of ICH: $51 \%$ for deep hemorrhage, $57 \%$ for lobar, $42 \%$ for cerebellar, and $65 \%$ for brain stem. ${ }^{7-11}$ Initial investigation methods include computed tomography (CT), magnetic resonance images (MRI) and digital substraction angiography (DSA). ${ }^{12,13}$

Hematoma can result in obstructive hydrocephalus and intracranial hypertension, which needs urgent treatment. Surgical and clinical measures have been used to control increased intracranial pressure (ICP). Clinical treatment includes infusion of manitol ${ }^{7,14}$ and initiators of hemostasis like recombinant factor VIIa. ${ }^{8,14}$ Surgical techniques include external ventricular drain $(\mathrm{EVD})^{2,15}$ and other minimally invasive techniques, such as endoscopic evacuation of a hematoma ${ }^{12,16}$ and stereotactic CT guided aspiration and thrombolysis. ${ }^{10,17}$

Supporting evidence from controlled trials is lacking, and according to the AHA/ASA Guidelines for the Management of Spontaneous Intracerebral Hemorrhage, the effectiveness of minimally invasive ICH evacuation utilizing the endoscopic method is still uncertain and the technique considered investigational. ${ }^{18}$ We described the technique of management of spontaneous deep cerebral hematoma by endoscopic approach.

\section{Methods}

Procedures were performed between may 2010 and march 2011 ( $n=13$; five men and eight women; age range 60-77 years; average age 66.5 years). Inclusion criteria were putaminal hematoma with volume greater than $30 \mathrm{ml}$, thalamic hematoma with volume greater than $20 \mathrm{ml}$, intraventricular bleeding with acute hydrocephalus, or subcortical hemorrhage greater than $30 \mathrm{ml}$ with significant mass effect (midline shift greater than $5 \mathrm{~mm}$ and effacement of perimesencephalic cistern) and neurological deterioration, and surgery within 12 hours after ictus.

All patients had hypertensive hemorrhages, investigated with CT scan, MRI and angio-MRI (to rule out vascular malformations or other vasculopathies). Pre and postoperative CT scan were performed in all patients (Figure 1). The surgical procedure was explained to the families of all the patients and informed consent was obtained.
A

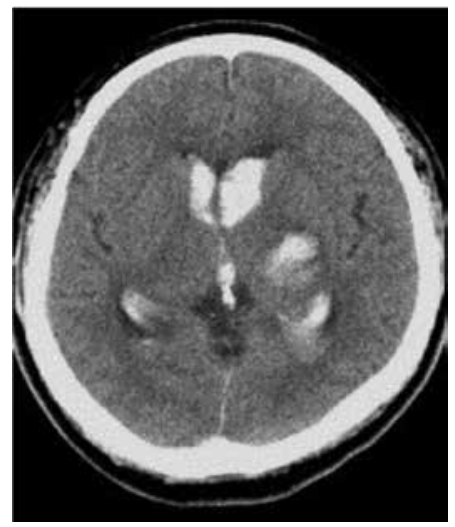

C

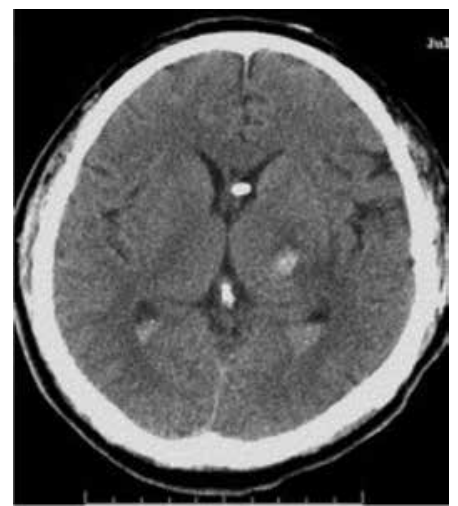

B

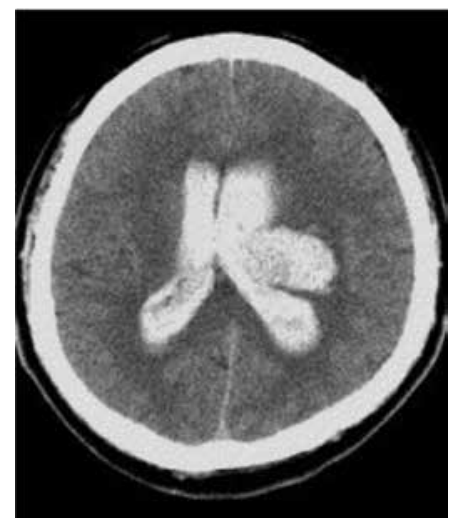

D

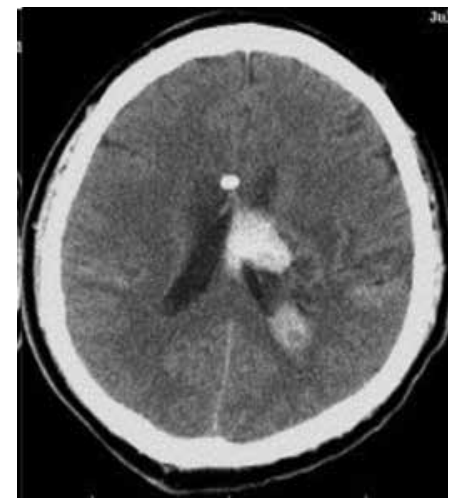

Figure 1 - Images of patient treated by neuroendoscopic approach of intracerebral hemorrhage. Before surgery (A and B) and after surgery (C and D) brain CT scan of thalamic hemorrhage treated by neuroendoscopy. 


\section{Technical note}

Approach was determined by the pre operative CT scan. For most putaminal ICHs the transtemporal approach was used. The frontal approach was used only when the frontal route provides the shortest distance between the cortical surface and the hematoma on the preoperative CT scan. Hemorrhages in the left side were approached through the inferior or medium temporal gyrus. Patients with right ICH were operated through the shortest distance to the hematoma, avoiding the central lobe.

After a general anesthesia, a linear skin incision (3-4 cm in length) was performed. In this point a 1.5 $\mathrm{cm}$ bur hole was made and dura mater was opened in cruciate fashion. Small corticotomy was made and a transparent plastic sheath was inserted pointed to the hematoma. Through this sheath a rigid endoscope $\left(18 \mathrm{~cm} 4-\mathrm{mm}^{\circ}\right)$ with irrigation system was introduced to provide visualization during hematoma removal.

A

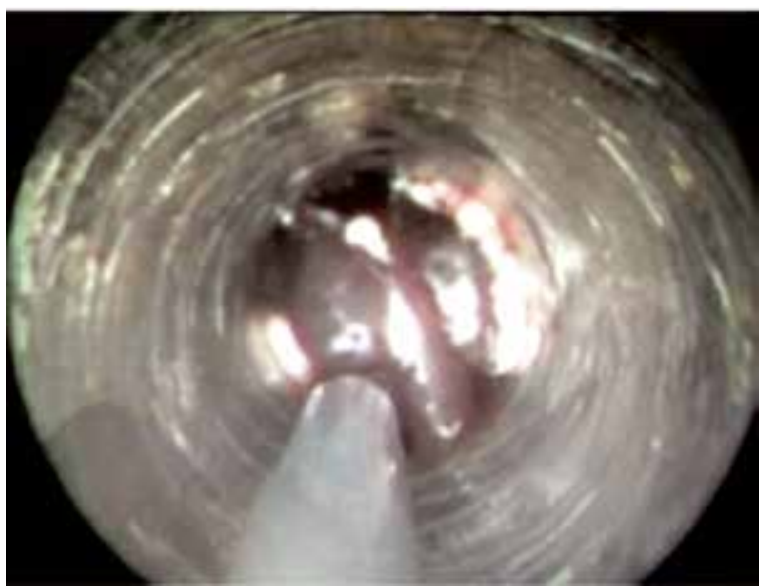

C

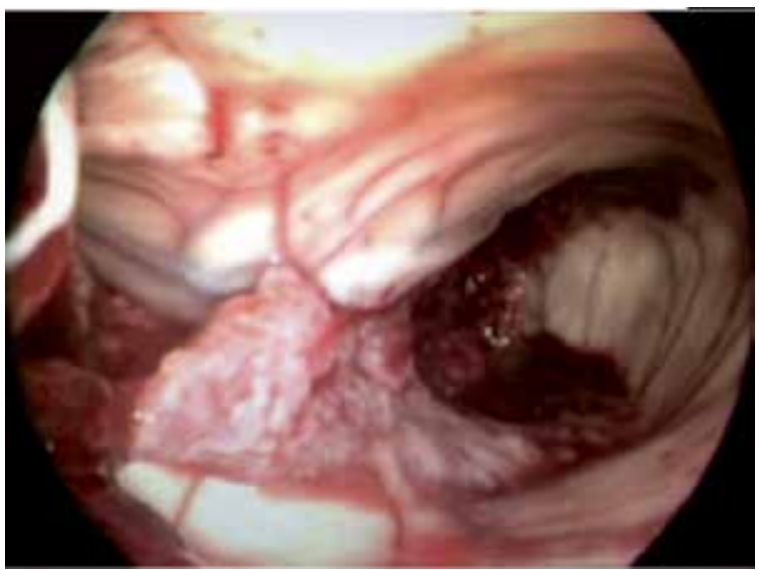

The hematoma was evacuated by direct endoscopic vision manipulating the suction through the working space within the sheath. The surgeon pointed the endoscope on the tip of the hematoma, and an assistant evacuated the hematoma by using a suction system. To avoid injury in the ventricular wall, the surgeon withdrew the endoscope by a few millimeters during evacuation. All procedure was performed with continuous irrigation of Ringer Solution (RS) to clarify the vision, clear the endoscopy tip and avoid ventricular collapse and ventricular wall injury during the surgery. Evacuation was stopped when the ventricle was clear and the aqueduct was visible. We did not insert the endoscope into the fourth ventricle or perform third ventriculostomy (Figure 2).

External ventricular drain (EVD) was performed at the end of the surgery, and intracranial pressure (ICP) was maintained at $200 \mathrm{~mm} \mathrm{H}_{2} \mathrm{O}$ by continuous CSF drainage. The EVD was discontinued using a cramp ring when the amount of CSF drained was less than $120 \mathrm{ml} /$ day and no obstruction of CSF in the whole ventricles was observed on a CT scan.

B

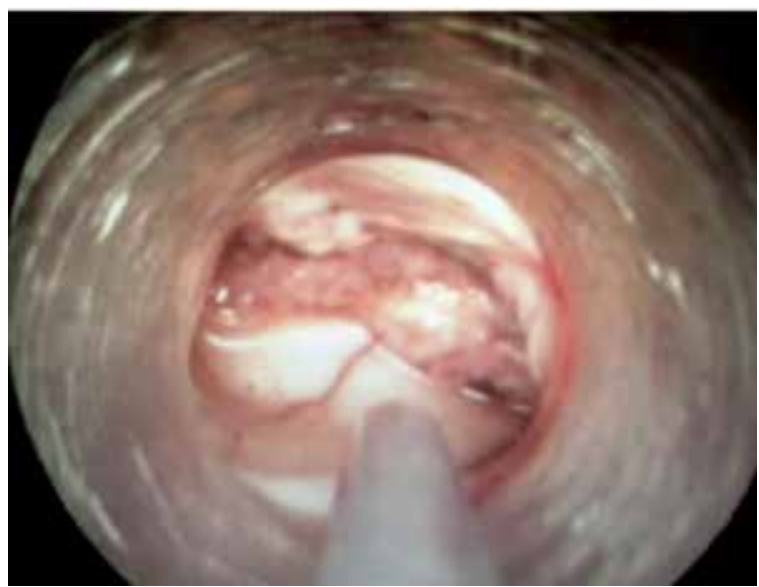

D

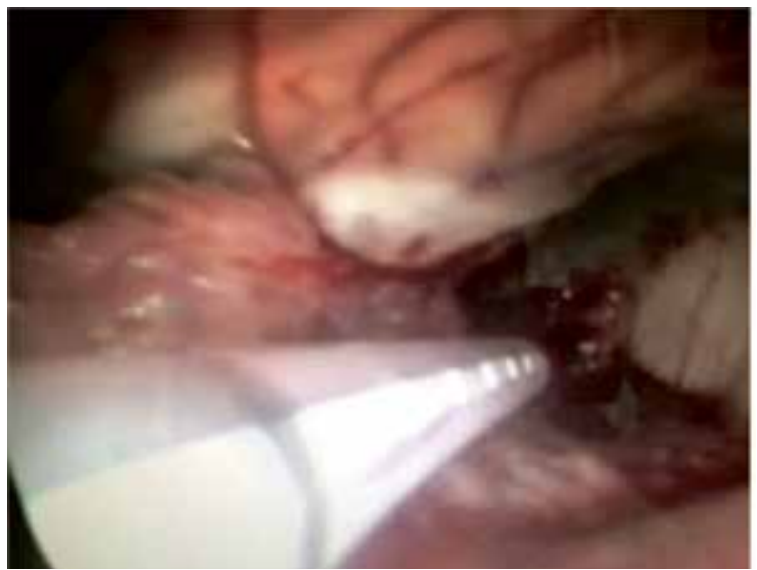

Figure 2 - Endoscopic treatment of thalamic hematoma. Visualization of hematoma (A); after evacuation (B); visualization of ventricular system (C) and EVD insertion (D). 


\section{Discussion}

AHA/ASA Guidelines for the Management of Spontaneous Intracerebral Hemorrhage don't state that ultra-early removal of supratentorial $\mathrm{ICH}$ improves functional outcomes or mortality rates. In addition, very early craniotomy would increase the risk of recurrent bleeding. That conclusion was based on a trial of $11 \mathrm{pa}-$ tients randomized within 4 hours of hemorrhage onset, where rebleeding rate was $40 \%$ in patients treated within 4 hours, compared with $12 \%$ of the patients treated within 12 hours using the craniotomy method., ${ }^{7,14}$ Recent series suggested that early and complete evacuation of $\mathrm{ICH}$ via a minimally invasive method could improve neurological outcome in these patients. ${ }^{3,6,18,20}$

Some studies suggested that the hematoma contributes to local mass effect and elevated ICP, increasing the pathological cascades resulting in a great neuroinflamatory and biochemical response. ${ }^{2,3,21-23}$ This finding could support that early and complete removal of $\mathrm{ICH}$ via a minimally invasive method could reduce the secondary injury associated with ICH. Theoretically, this should lead to improved functional outcomes and decreased mortality rates.

Authors believe that endoscope-assisted ICH evacuation performed in the early stage was associated with a minimal rebleeding rate (0\%-3.3\%) compared with the traditional craniotomy method (5\%-10\%). ${ }^{1,2}$ Other advantages of the endoscope-assisted method include low complication rate, less operative time, less blood loss, improved evacuation rate, and early recovery of the patients. ${ }^{2,5,15,20,24}$

Neuroendoscopic technique may provide a better hematoma evacuation rate with minimal damage to normal brain tissue. Due to the improvement of neuroendoscopic systems and instruments, recent series have shown high rates of hematoma evacuation that ranged from $83.4 \%$ to $99 \%$. ${ }^{1,3,10,12,16}$

Studies suggested that surgery should be performed within 24 hours after onset, because intracerebral hematoma usually starts to harden about 24 hours after onset and 48 hours later it can't be evacuated with a suction tube. ${ }^{10,14,25}$

An important decision is choose the better approach (the frontal or temporal approach). The frontal approach was recommended by the authors in these cases due to its involving noneloquent regions and providing better visualization that may result in maximal hematoma evacuation. ${ }^{715,26}$ The frontal approach may pass through the lenticulostriate arteries, causing intraoperative bleeding and worse outcomes. ${ }^{17}$ This may explain the high incidence of intraoperative bleeding [9 (82\%) of 11 cases] in one series in which the frontal approach was used. ${ }^{10}$

When temporal approach was choice for putaminal $\mathrm{ICH}$, evacuation could be accomplished in approxima- tely $70 \%$ of the cases without obvious intraoperative bleeding. Other advantage was the shorter working distance, which increases the comfort of the procedure and facilitates deftness. When a frontal approach was used, we usually performed the bur hole in a more lateral position.

Cases of acute bleeding were controlled using the bipolar coagulator, and we did not place a drainage tube within the hematoma cavity after securing hemostasis. Our study also demonstrated that the use of a hemostatic agent for noncoagulation hemostasis seems to be safe because the rebleeding rate was very low.

\section{Conclusions}

This study showed that early and complete evacuation of ICH could lead to improved outcomes in selected patients. Also, early endoscope-assisted ICH evacuation is safe and effective in the management of supratentorial ICH.

\section{References}

1. Chen CC, Cho DY, Chang CS, Chen JT, Lee WY, Lee HC. A stainless steel sheath for endoscopic surgery and its application in surgical evacuation of putaminal haemorrhage. J Clin Neurosci. 2005;12(8):937-40.

2. Longatti PL, Martinuzzi A, Fiorindi A, Maistrello L, Carteri A. Neuroendoscopic management of intraventricular hemorrhage. Stroke. 2004;35(2):e35-8.

3. Chen CC, Lin HL, Cho DY. Endoscopic surgery for thalamic hemorrhage: a technical note. Surg Neurol. 2007;68(4): 438-42.

4. Cho DY, Chen CC, Chang CS, Lee WY, Tso M. Endoscopic surgery for spontaneous basal ganglia hemorrhage: comparing endoscopic surgery, stereotactic aspiration, and craniotomy in noncomatose patients. Surg Neurol. 2006;65(6):547-55.

5. Fewel ME, Thompson BG Jr, Hoff JT. Spontaneous intracerebral hemorrhage: a review. Neurosurg Focus. 2003;15(4):E1.

6. Nishihara T, Morita A, Teraoka A, Kirino T. Endoscopyguided removal of spontaneous intracerebral hemorrhage: comparison with computer tomography-guided stereotactic evacuation. Childs Nerv Syst. 2007;23(6):677-83.

7. Hamada $\mathrm{H}$, Hayashi $\mathrm{N}$, Kurimoto $\mathrm{M}$, Umemura $\mathrm{K}$, Nagai $\mathrm{S}$, Kurosaki K, et al. Neuroendoscopic removal of intraventricular hemorrhage combined with hydrocephalus. Minim Invasive Neurosurg. 2008;51(6):345-9.

8. Hsieh PC, Cho DY, Lee WY, Chen JT. Endoscopic evacuation of putaminal hemorrhage: how to improve the efficiency of hematoma evacuation. Surg Neurol. 2005;64(2):147-53.

9. Zhang Z, Li X, Liu Y, Shao Y, Xu S, Yang Y. Application of neuroendoscopy in the treatment of intraventricular hemorrhage. Cerebrovasc Dis. 2007;24(1):91-6. 
10. Zuccarello M, Brott T, Derex L, Kothari R, Sauerbeck L, Tew J, et al. Early surgical treatment for supratentorial intracerebral hemorrhage: a randomized feasibility study. Stroke. 1999;30(9):1833-9.

11. Morgenstern LB, Demchuk AM, Kim DH, Frankowski RF, Grotta JC. Rebleeding leads to poor outcome in ultraearly craniotomy for intracerebral hemorrhage. Neurology. 2001;56(10):1294-9.

12. Nagasaka $\mathrm{T}$, Tsugeno $\mathrm{M}$, Ikeda $\mathrm{H}$, Okamoto $\mathrm{T}$, Takagawa $\mathrm{Y}$, Inao S, et al. Balanced irrigation-suction technique with a multifunctional suction cannula and its application for intraoperative hemorrhage in endoscopic evacuation of intracerebral hematomas: technical note. Neurosurgery. 2009;65(4):E826-7.

13. Longatti P, Fiorindi A, Martinuzzi A. Neuroendoscopic aspiration of hematocephalus totalis: technical note. Neurosurgery. 2005;57(Suppl 4):E409.

14. Yadav YR, Mukerji G, Shenoy R, Basoor A, Jain G, Nelson A. Endoscopic management of hypertensive intraventricular haemorrhage with obstructive hydrocephalus. BMC Neurol. 2007;7:1.

15. Anzai K, Kamiyama K, Sasaki T, Nakamura H. Endoscopic evacuation of intraventricular hematoma and third ventriculostomy. No Shinkei Geka. 2000;28(7):599-605.

16. Barbagallo GM, Platania N, Schonauer C. Long-term resolution of acute, obstructive, triventricular hydrocephalus by endoscopic removal of a third ventricular hematoma without third ventriculostomy. Case report and review of the literature. J Neurosurg. 2005;102(5):930-4.

17. Mendelow AD, Gregson BA, Fernandes HM, Murray GD, Teasdale GM, Hope DT, et al. STICH investigators. Early surgery versus initial conservative treatment in patients with spontaneous supratentorial intracerebral haematomas in the International Surgical Trial in Intracerebral Haemorrhage (STICH): a randomised trial. Lancet. 2005;365(9457):387-97.

18. Nagasaka $\mathrm{T}$, Inao $\mathrm{S}$, Ikeda $\mathrm{H}$, Tsugeno $\mathrm{M}$, Okamoto $\mathrm{T}$. Inflation-deflation method for endoscopic evacuation of intracerebral haematoma. Acta Neurochir (Wien). 2008;150(7):685-90.

19. Nieuwkamp DJ, De Gans K, Rinkel GJ, Algra A. Treatment and outcome of severe intraventricular extension in patients with subarachnoid or intracerebral hemorrhage: a systematic review of the literature. J Neurol. 2000;247(2):117-21.

20. Nyquist P, LeDroux S, Geocadin R. Thrombolytics in intraventricular hemorrhage. Curr Neurol Neurosci Rep. 2007;7(6):522-8.

21. Pantazis G, Tsitsopoulos P, Mihas C, Katsiva V, Stavrianos $\mathrm{V}$, Zymaris $\mathrm{S}$. Early surgical treatment vs conservative management for spontaneous supratentorial intracerebral hematomas: a prospective randomized study. Surg Neurol. 2006;66(5):492-501.

22. Nagasaka T, Tsugeno M, Ikeda H, Okamoto T, Inao S, Wakabayashi T. Early recovery and better evacuation rate in neuroendoscopic surgery for spontaneous intracerebral hemorrhage using a multifunctional cannula: preliminary study in comparison with craniotomy. J Stroke Cerebrovasc Dis. 2011;20(3):208-13.

23. Nakano T, Ohkuma H, Ebina K, Suzuki S. Neuroendoscopic surgery for intracerebral haemorrhage - comparison with traditional therapies. Minim Invasive Neurosurg. 2003;46(5):278-83.

24. Nishihara T, Teraoka A, Morita A, Ueki K, Takai K, Kirino T. A transparent sheath for endoscopic surgery and its application in surgical evacuation of spontaneous intracerebral hematomas. Technical note. J Neurosurg. 2000;92(6):1053-5.

25. Zuo Y, Cheng G, Gao DK, Zhang X, Zhen HN, Zhang W, et al. Gross-total hematoma removal of hypertensive basal ganglia hemorrhages: a long-term follow-up. J Neurol Sci. 2009;287(1-2):100-4.

26. Nishikawa T, Takehira N, Matsumoto A, Kanemoto M, Kang Y, Waga S. Delayed endoscopic intraventricular hemorrhage (IVH) removal and endoscopic third ventriculostomy may not prevent consecutive communicating hydrocephalus if IVH removal was insufficient. Minim Invasive Neurosurg. 2007;50(4):209-11.

\section{Endereço para correspondência}

Flávio Ramalho Romero

Rua Distrito de Rubião Júnior, $s / n$, Rubião Jr.

18618-970 - Botucatu, SP, Brazil

Telefones: (14) 3811-6260/(14) 3811-6000

E-mails:frromero@ig.com.br/romeroncr@gmail.com 